\title{
Experimental study on the dynamic thermal response of a radiant floor system in an office building
}

\author{
Jing Ren ${ }^{1}$, Meng Su${ }^{1}$, Xintian Zhao ${ }^{1}$, Jiying Liu ${ }^{1,2^{*}}$, Shoujie Song ${ }^{3}$ \\ ${ }^{1}$ School of Thermal Engineering, Shandong Jianzhu University, Jinan 250101, China \\ ${ }^{2}$ Built Environment Design and Research Institute, Shandong GRAD Group Co. Ltd., Dezhou 253000, China \\ ${ }^{3}$ Building Energy Conservation Research Institute, Shandong Antaeus Intelligent and Engineering Co. Ltd., Jinan 250101, China
}

\begin{abstract}
The dynamic thermal performance of radiant terminal plays an important role in the design and control of radiant cooling system, which is shown as the dynamic thermal response of radiant floor system (RFS) under imposed control. In this paper, the field measurement method was used to study the dynamic thermal response of RFS. The RFS was activated in summer and the supply water temperature was regulated in winter to make dynamic change of thermal performance. The floor surface temperature was selected as the characteristic parameter to describe the dynamic heat transfer performance of the system, and response time $\tau_{95}$ and time constant $\tau_{63}$ were used to quantify the dynamic thermal response. The maximum $\tau_{95}$ was $13.5 \mathrm{~h}$ and $\tau_{95} / \tau_{63}$ was greater than or equal to 2 in the cooling mode, while $\tau_{95}$ and $\tau_{63}$ were both less than $10 \mathrm{~h}$ and $\tau_{95} / \tau_{63}$ was 1.6 in the heating mode. As a result, there was no significant lessening of temperature change rate, and the thermal response of RFS was faster under intermittent control of supply water temperature in winter. Therefore, the study aims at providing reference for making intermittent control strategy by using the dynamic thermal performance of radiant system.
\end{abstract}

Keywords: radiant floor system, dynamic thermal performance, response time, time constant

* Corresponding author: jx183@sdjzu.edu.cn (Jiying Liu) 


\section{Introduction}

Since the 21 st century, an increasing amount of attention has been given to energy saving due to emission reduction goals, and the rapid development of HVAC technology and radiant cooling/heating air conditioning systems, which represent large portions of building energy budgets, have received an especially high amount attention. Many studies have been conducted on thermal comfort and energy efficiency of radiant cooling/heating systems [1-3]. High-temperature cooling and low-temperature heating systems use lower-grade cold and heat sources [4], this provides favorable conditions for the further promotion and application of radiant terminals. Therefore, the system has great energy saving potential [5]. Radiant floor systems (RFS) transfer heat between the radiant surface and the surroundings via indoor air convective heat transfer and radiative heat transfer. Radiative heat transfer accounts for more than $50 \%$ of the total heat transfer in the radiant system [6], increasing the radiative heat transfer with the human body, thus making it central to improving thermal comfort. However, the regulation of radiant systems is more complicated than conventional air systems because the response time of the radiant system is significantly longer $[7,8]$. Therefore, accurate control strategies are required to ensure effective operation and meet thermal comfort standards under dynamic weather conditions and indoor heat gain.

Response time $\tau_{95}$ and time constant $\tau_{63}$ are widely used for evaluating the dynamic thermal performance of radiant systems to reflect if a radiant system response is fast or slow. Ning et al. [9] found that $\tau_{95}$ could provide a more consistent metric of long-term thermal response of the full range of radiant system types. Merabtine et al. [10] proposed a simplified analytical model with $\tau_{63}$ and delay time for the average floor heating surface temperature. Thermal performance of the radiant terminal can be effectively used by applying an intermittent control strategy combined with controlling supply water temperature and flow rate in radiant panels, this contributes to improve response time. Liu et al. [11] showed that the energy consumption decreased by $3.3 \%$ to $7.5 \%$ when the different intermittent operation strategies using thermal characteristic of the building were applied. Hu et al. [12] found that radiant cooling system conserved cooling energy in unoccupied period to balance $9-15 \%$ of indoor heat gain in occupied period, and the peak sensible cooling loads of the radiant terminal decreased by $32-39 \%$ compared with those using conventional scheduling. Sui et al. [13] observed that increasing the start and stop frequency of the pump during a given cooling period increased the cooling capacity of a tubes-embedded envelope cooling system. Liu et al. [14] proposed intermittent controls based on the minimum outdoor air temperature and the average water supply and return temperature via CFD simulation Tang et al. [15] proposed a novel pulse flow control method that allowed for a $27 \%$ reduction of the supply water flow at $50 \%$ load operation, and it made the radiant surface temperature distribution more uniform with more accurate control.

Moreover, the unique thermal characteristics of RFS is affected by the indoor environment and outdoor weather conditions, emphasizing the importance of experimental research in the practical applications of RFS. Therefore, it is crucial to test thermal performance of radiant terminal under concrete control in the practical building.

In this paper, the field measurement method was used to study the dynamic thermal response of RFS. The experimental room created a real-world scenario in which changes in thermal and humidity parameters in the room were influenced by outdoor weather conditions. The dynamic thermal response of RFS was caused by different imposed control, which were supply water temperature regulation in summer and start-up control in winter respectively. The change of floor surface temperature during the process of heat exchange between radiant floor and buried pipe water was analyzed. In addition, the $\tau_{95}, \tau_{63}$ and $\tau_{95} / \tau_{63}$ of the RFS under different imposed controls in winter and summer were compared, and the differences along with the effect of two imposed controls on thermal response were obtained.

\section{Methods}

\subsection{Experimental scenario description}

The field test was conducted in a south facing room with a floor area of $50 \mathrm{~m}^{2}$ on the fifth (top) floor of an 
office building in Jinan. Jinan is located in the north of China, which is in a cold region as shown in Figure 1.

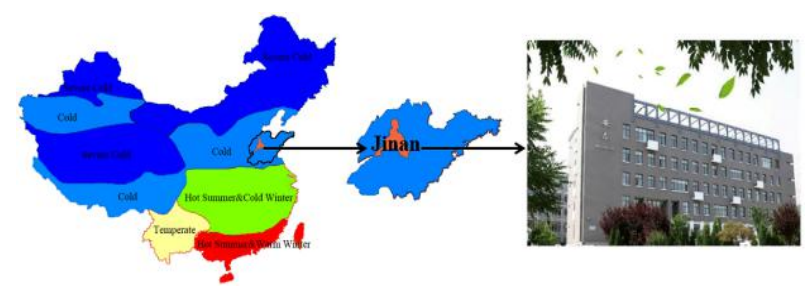

Figure 1 The climate location of Jinan and an outdoor view of the office building.

The heat transfer coefficient of the exterior wall is $0.6 \mathrm{~W} /\left(\mathrm{m}^{2} \cdot \mathrm{K}\right)$, that of the roof is $0.55 \mathrm{~W} /\left(\mathrm{m}^{2} \cdot \mathrm{K}\right)$, that of the floor was $1.03 \mathrm{~W} /\left(\mathrm{m}^{2} \cdot \mathrm{K}\right)$, and that of the external window is $2.4 \mathrm{~W} /\left(\mathrm{m}^{2} \cdot \mathrm{K}\right)$ [16]. The schematic diagram and thermophysical parameters of radiant floor are respectively shown in Figure 2 and Table 1 [14].

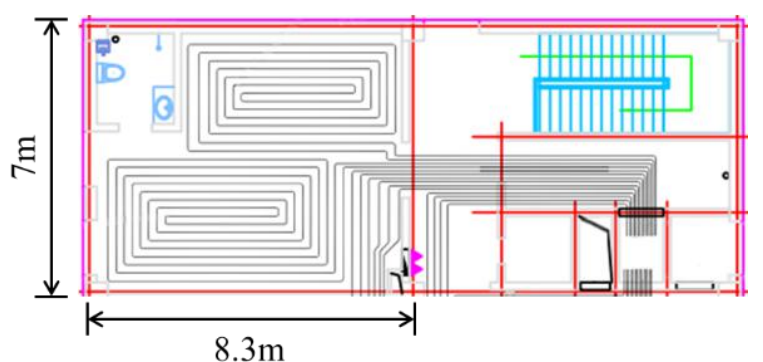

(a)

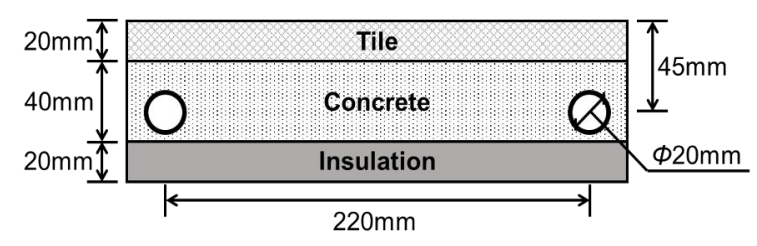

(b)

Figure 2 Schematic diagram, (a) distribution of buried pipes in the experimental room, and (b) structure of radiant floor.

Table 1 Thermophysical parameters of layers of radiant floor

\begin{tabular}{ccc}
\hline Layers & $\begin{array}{c}\text { Conductivity } \\
(\mathrm{W} / \mathrm{m} \cdot \mathrm{K})\end{array}$ & $\begin{array}{c}\text { Specific Heat } \\
(\mathrm{J} / \mathrm{kg} \cdot \mathrm{K})\end{array}$ \\
\hline Tile & 2.1 & 950 \\
Light concrete & 1.45 & 1000 \\
Pipe embedded & 0.4 & 1000 \\
Insulation & 0.022 & 4600 \\
\hline
\end{tabular}

\subsection{Experimental setup}

The RFS is depicted in Figure 3. During summer the cooling energy supplied to the radiant terminal comes entirely from the ground heat exchanger and the heat pump unit was by-passed. Therefore, the underground pipe water was directly supplied to the room without cooling by the heat pump unit. During winter the supply water temperature in the buried pipe was controlled by the heat pump unit. The supply water temperature was heated to the appropriate temperature based on indoor requirement and sent to the room to provide heating for indoor environment.

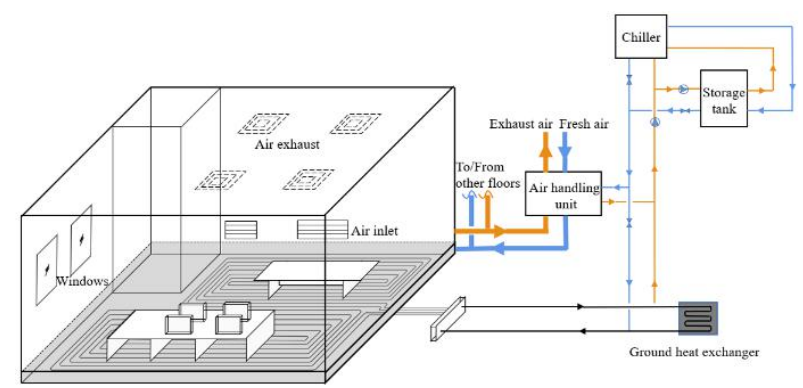

Figure 3 Schematic diagram of the RFS.

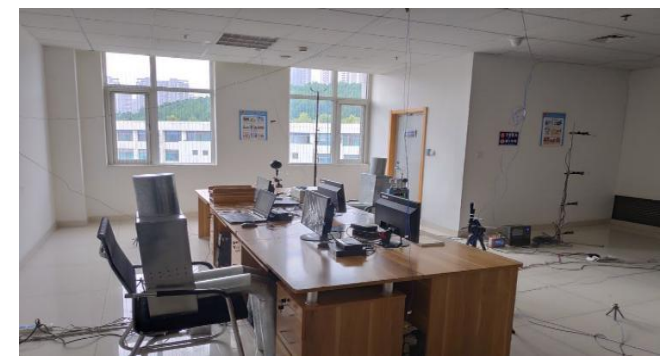

Figure 4 The field test environment in the office room.

The field test environment is shown in Figure 4. The measurement parameters included supply and return water temperatures and flow rates, floor surface temperature, wall and ceiling temperatures, room air temperature. The layout of surface temperature and supply and return water measuring points is shown in Figure 5. The four floor surface temperature measuring points were placed near walls to the east, west, north, and south of the room in summer. Other six floor surface temperature measuring points (red) added were placed along the flow direction of supply water in the middle of the room in winter. The wall temperature measuring points were centered on their respective walls, and ceiling measuring points were uniformly distributed on the ceiling. One indoor air parameter measuring point was placed at the vertical height of 1.1 $\mathrm{m}$ in the center of the room, and other six measuring points at vertical heights of $0.1 \mathrm{~m}$ were uniformly distributed in the room. The supply and return water temperature measuring points were placed at manifolds on the supply and return water pipes. The detailed parameters of experimental equipment are shown in 
Table 2.

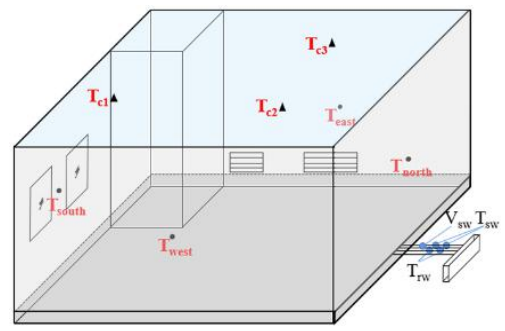

(a)

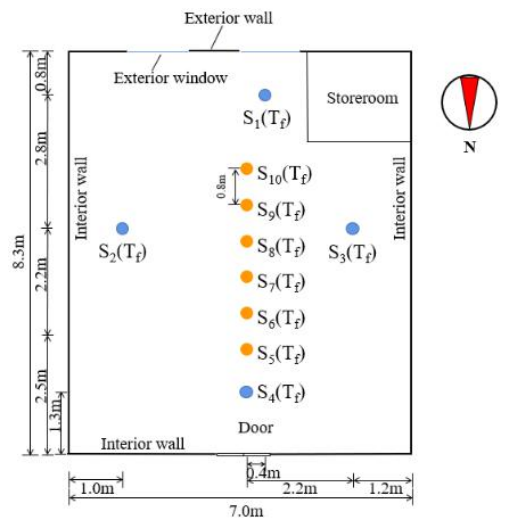

(b)

Figure 5 Layout of measuring point, (a) full view of wall and ceiling temperature measuring points, and (b) top view of $T_{f}$ measuring points.

Table 2 Summary of the experiment instruments.

\begin{tabular}{llll}
\hline Parameters & Instruments & Range & Accuracy \\
\hline$T_{i n}$ & JTR08B & $-20 \sim 80^{\circ} \mathrm{C}$ & $\pm 0.5^{\circ} \mathrm{C}$ \\
$T_{f}$ & DT-3891G & $-20 \sim 200^{\circ} \mathrm{C}$ & $\pm 0.5^{\circ} \mathrm{C}$ \\
$T_{s}$ & JTNT-F60 & $-20 \sim 200^{\circ} \mathrm{C}$ & $\pm 0.5^{\circ} \mathrm{C}$ \\
$T_{s w}$ & DT-3891G & $-20 \sim 200^{\circ} \mathrm{C}$ & $\pm 0.5^{\circ} \mathrm{C}$ \\
$V_{s w}$ & $\mathrm{~K} 28$ & $0.1 \sim 10 \mathrm{~L} / \mathrm{min}$ & $\pm 1 \%$ \\
\hline
\end{tabular}

\subsection{Experimental schemes}

Table 3 shows the imposed control leading to dynamic thermal response of floor radiant system in experiment. During summer, the RFS stopped operation at the end of weekday due to longer unoccupied duration on weekends. Aug. 16 and Aug. 23 were Sunday and selected as typical dates. Water supply of RFS was started at 17:00 and 13:00 respectively on these two days based on $T_{f}$ level, causing $T_{f}$ to decrease. During winter, $T_{s w}$ of the RFS was controlled to decrease after work. The typical dates of Jan. 13 and Jan. 14 were adjacent days during weekdays. The excessive decrease of $T_{f}$ was avoided because of the heat stored in the radiant terminal. $T_{s w}$ was increased to $28.4^{\circ} \mathrm{C}$ at $23: 30$ on Jan. 13 and to $29.4^{\circ} \mathrm{C}$ at $24: 00$ on Jan. 14 when it decreased to $23 \sim 24^{\circ} \mathrm{C}$, and accordingly
$T_{f}$ increased. $T_{s w}$ on Aug. 16 and Jan. 13 were described in Figure 6.

Table 3 Imposed controls of RFS on typical dates

\begin{tabular}{ccc}
\hline Date & Control time & Imposed control \\
\hline Aug. 16 & $17: 00$ & Start water supply \\
Aug. 23 & $13: 00$ & \\
Jan. 13 & $23: 30$ & Increase $T_{s w}$ to $28.4^{\circ} \mathrm{C}$ \\
Jan. 14 & $24: 00$ & Increase $T_{s w}$ to $29.4^{\circ} \mathrm{C}$ \\
\hline
\end{tabular}

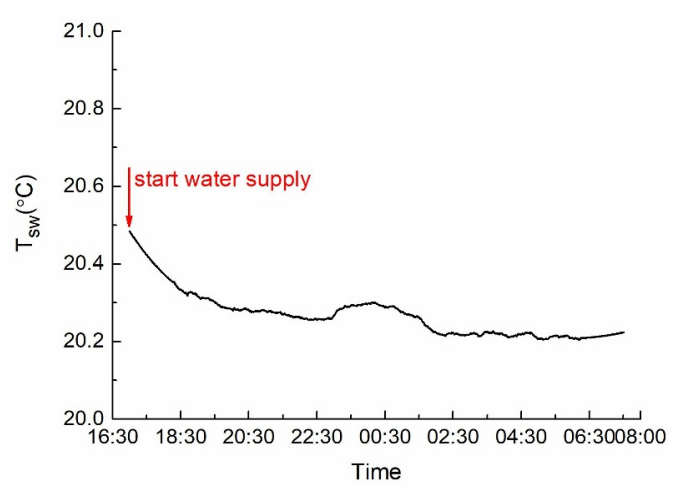

(a)

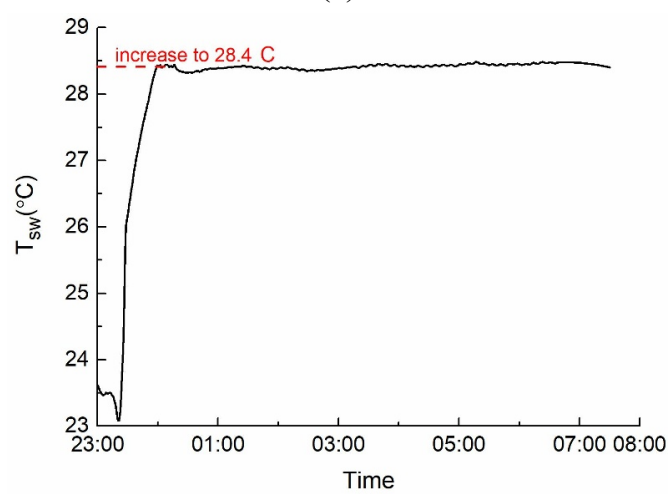

(b)

Figure 6 Imposed control of $T_{s w}$, (a) $T_{s w}$ on Aug. 16, and (b) $T_{s w}$ on Jan. 13.

\subsection{Thermal response evaluation index}

In this paper, the radiant surface temperature was selected as the characteristic parameter to describe the dynamic heat transfer performance of the radiant terminal. The radiant surface temperature is mainly affected by the water circulated in buried pipe, which can better reflect the heat transfer between the buried pipe water and the radiant panel, and the heat transfer between the radiant panel and the indoor thermal environment.

Meanwhile, $\tau_{63}$ and $\tau_{95}$ were used to describe the thermal response of radiant terminal. $\tau_{63}$ is generally used to describe dynamic thermal response of radiant terminal, which is defined as the time taken to achieve 
$63 \%$ of the total temperature change, which can be used to measure the time required for radiant terminal from the beginning to stable heat transfer [17]. However, $\tau_{63}$ can only describe dynamic thermal performance of the radiant terminal at the early period, but cannot reflect the whole process from one stable condition to another. Therefore, it is required to combine $\tau_{95}$ which is the time it takes for radiant surface temperature of a radiant system to reach $95 \%$ of the difference between its final and initial values[8]. The time that achieving 95\% of the total temperature change is very close to the final steady state. Thus, $\tau_{95}$ can be used to well describe thermal response of radiant terminal from one stable to another.

Moreover, variable heat transfer between radiant floor and buried pipe water was also used to show dynamic change of thermal performance of radiant terminal, which could be calculated based on the temperature difference and thermal resistance between radiant surface and buried pipe water. Chilled/hot water circulated in embedded surface system provide cooling/heating for radiant terminal, and then heat is transferred between radiant terminal and indoor environment via convective heat transfer and radiative heat transfer. Cooling/heating provided by buried pipe water can be calculated by Eq (1).

$$
Q=\left|T_{s}-\bar{T}_{w}\right| / R-q_{\text {stored }} \cdots
$$

where, $Q$ is cooling/heating provided by buried pipe water, $\mathrm{W} / \mathrm{m}^{2} ; T_{s}$ is radiant surface temperature, ${ }^{\circ} \mathrm{C}, \bar{T}_{w}$ is supply and return water temperature, ${ }^{\circ} \mathrm{C}, R$ is thermal resistance between radiant surface and buried pipe water, $\left(\mathrm{K} \cdot \mathrm{m}^{2}\right) / \mathrm{W}$, and $q_{\text {store }}$ is the cooling energy used to remove the heat accumulated in radiant floor, $\mathrm{W} / \mathrm{m}^{2}$.

\section{Results and discussion}

\subsection{Thermal response under imposed control in the cooling mode}

Figure 7 shows the changes of $T_{f}, T_{i n}$ and $Q_{c}$ after the start-up of RFS in summer. In the beginning when chilled water started to be supplied, $T_{f}$ was the highest due to the heat storage in radiant terminal and indoor heat accumulation, along with the maximum heat transfer between the floor and water supply because of the greatest temperature difference between the two. With the continuous cooling supplied by chilled water,
$T_{f}$ and heat removed by chilled water gradually decreased, while the decreasing gradient of $T_{f}$ tended to lessen. The decreasing rate of $T_{f}$ after $\tau_{63}$ was smaller than that during $\tau_{63}$.

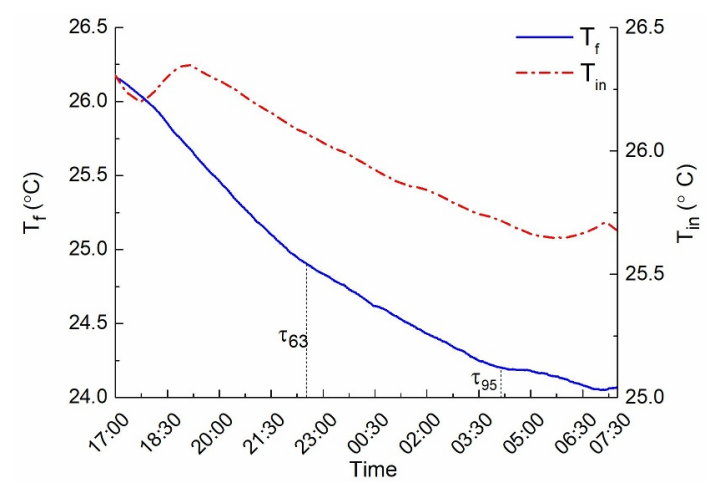

(a)

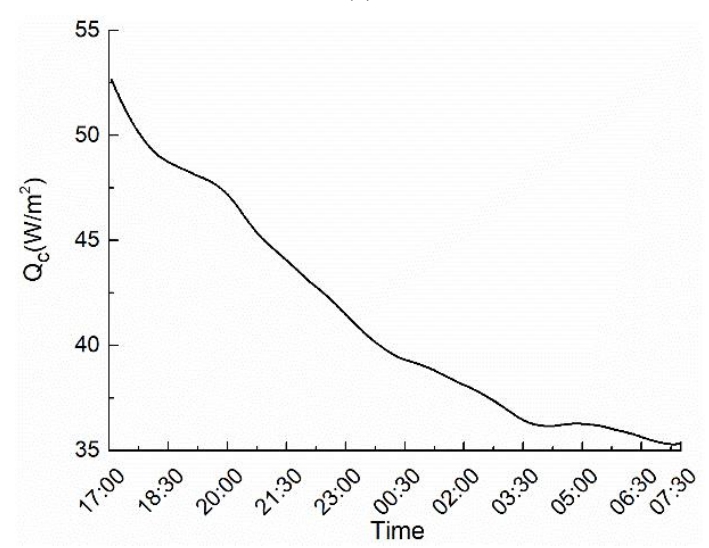

(b)

Figure 7 Thermal response when activating RFS (a) $T_{f}$ and $T_{\text {in }}$ reduction process when activating RFS, and (b) $Q_{c}$ decaying process when activating RFS.

When approaching 95\% of the total temperature change, $T_{f}$ decreased slowly, and essentially stabilized after a small decrease. The RFS was combined with displacement ventilation system for cooling in summer. After the RFS was started, $T_{f}$ was higher due to shutdown of displacement ventilation system so that the insufficient cooling caused $T_{i n}$ to increase in a short time. When $T_{f}$ decreased by about $1{ }^{\circ} \mathrm{C}$, cooling capacity of RFS could counter indoor heat gain and achieve cooling effect, and therefore $T_{i n}$ began to decrease. With the decrease of heat transfer between chilled water and radiant floor, $T_{\text {in }}$ gradually remained a stable level.

\subsection{Thermal response under imposed control in the heating mode}

The changes of $T_{f}, T_{i n}$ and $Q_{h}$ after $T_{s a}$ of RFS increased in winter are illustrated in Figure 8. $T_{s w}$ decreased by $2 \sim 3^{\circ} \mathrm{C}$ after working period, and 
meanwhile heat stored in radiant terminal gradually released. When $T_{s w}$ increased to $28.4^{\circ} \mathrm{C}, T_{f}$ was at the lowest level, and the temperature difference between the two was the greatest, so the heat transfer from hot water was maximum at initial time.

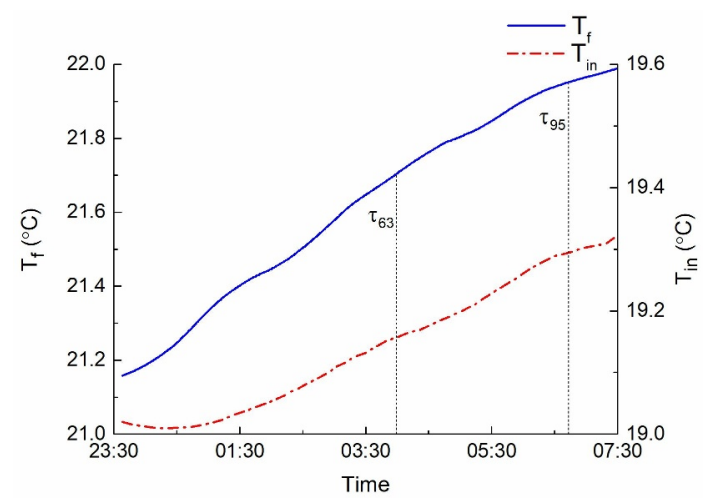

(a)

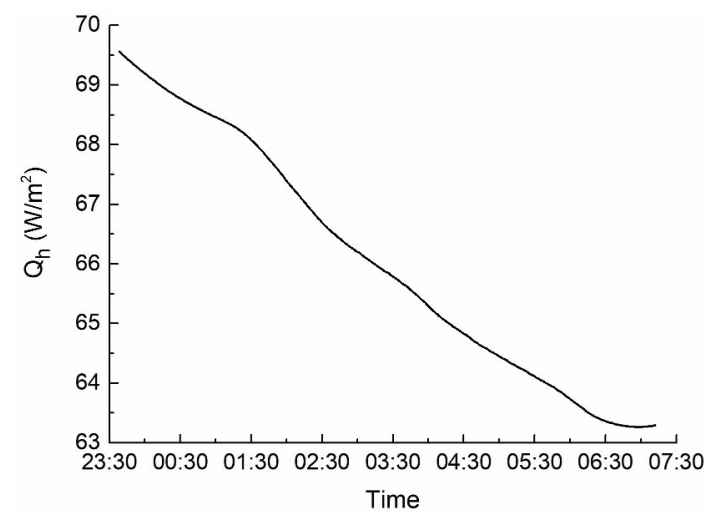

(b)

Figure 8 Thermal response when increasing $T_{s w}$, (a) $T_{f}$ and $T_{\text {in }}$ increasing process when increasing $T_{s w}$, and (b) $Q_{h}$ decaying process when increasing $T_{s w}$.

Affected by hot water flowing in the radiant terminal, $T_{f}$ increased continuously, heating provided by hot water decreased gradually since the temperature difference between radiant floor and hot water kept decreasing, and the increasing trend of $T_{f}$ slowed down. $\tau_{63}$ was approximately half of the total $T_{f}$ change time, along with the similar decreasing gradient of $T_{f}$ before and after this time. Heating provided by hot water became stable, and the temperature changed more slightly after $\tau_{95}$. While $T_{\text {in }}$ did not increase immediately with increase of $T_{f}$ until the RFS operated with high $T_{f}$ for half an hour. As the heating transfer tended to balance, $T_{\text {in }}$ increased slightly.

\subsection{Comparation of thermal response in the cooling and heating mode}

$T_{f}$ at different stage and parameters reflecting the thermal response of the RFS in winter and summer are listed in Table 4. The dynamic thermal response of RFS in winter and summer was caused by different controls including increasing $T_{s a}$ and initiating water supply. It was inferred that $\tau_{95} / \tau_{63}$ was greater than or equal to 2 in the cooling mode and 1.6 in the heating mode. According to the radiant system categories in the literature [8], the radiant floor of the experimental room was classified as type A. $\tau_{95}$ of the RFS in the cooling mode was close to or even surpassed the range from 3 to $13 \mathrm{~h}$ under different impact factors obtained from the literature [8]. It was related to the fact that the RFS used underground pipe water for cooling in summer, and higher $T_{s a}$ had less effect on the thermal performance of the radiant terminal. While $\tau_{95}$ of the RFS in the heating mode was at higher level within range of $2.9 \sim 11.8 \mathrm{~h}$ provided by the literature [8]. It could be concluded that $T_{s a}$ regulation in winter can lead to the faster change of $T_{f}$, making the thermal response of RFS faster.

Table $4 T_{f}$ at different stage and thermal response parameters

\begin{tabular}{|c|c|c|c|c|c|c|c|}
\hline Modes & Date & $\begin{array}{l}T_{0} \\
\left({ }^{\circ} \mathrm{C}\right)\end{array}$ & $\begin{array}{l}\tau_{63} \\
(\mathrm{~h})\end{array}$ & $\begin{array}{l}T_{63} \\
\left({ }^{\circ} \mathrm{C}\right)\end{array}$ & $\begin{array}{l}\tau_{95} \\
(\mathrm{~h})\end{array}$ & $\begin{array}{l}T_{95} \\
\left({ }^{\circ} \mathrm{C}\right)\end{array}$ & $\begin{array}{l}T_{100} \\
\left({ }^{\circ} \mathrm{C}\right)\end{array}$ \\
\hline \multirow{2}{*}{$\begin{array}{l}\text { Cooling } \\
\text { mode }\end{array}$} & $\begin{array}{l}\text { Aug. } \\
16\end{array}$ & 26.2 & 5.5 & 24.9 & 11.2 & 24.2 & 24.1 \\
\hline & $\begin{array}{l}\text { Aug. } \\
23\end{array}$ & 25.7 & 6 & 24.4 & 13.5 & 23.7 & 23.6 \\
\hline \multirow{2}{*}{$\begin{array}{l}\text { Heating } \\
\text { mode }\end{array}$} & $\begin{array}{l}\text { Jan. } \\
13\end{array}$ & 21.1 & 4.5 & 21.7 & 7.2 & 21.9 & 22 \\
\hline & $\begin{array}{l}\text { Jan. } \\
14\end{array}$ & 22 & 5 & 22.6 & 8 & 22.8 & 22.9 \\
\hline
\end{tabular}

\section{Discussion}

The RFS operated 24h during weekdays entirely depending on the underground pipe water for cooling in summer. Therefore, lack of intermittent control led to few cases of thermal response of the radiant terminal, and the heat exchange was small between the radiant floor and buried pipe water, which caused longer response time of radiant terminal. The thermal response of radiant floor is that the radiant floor changes from one stable condition to another under the control signal, and the time constant is used to describe the response rate of the system. Intermittent heat transfer caused the floor surface temperature to change. The change rate of 
floor surface temperature gradually decreased with continuous heat transfer between supply water and radiant floor. This period was the main part of the thermal response, which had a great influence on the time constant. The floor surface temperature was eventually stable, and maintained a small temperature difference of relatively stability with supply water temperature, achieving heat transfer balance. At this period, radiant floor was in a stable condition, and the small temperature difference impacted little on the time constant. In the future, it is necessary to use the dynamic thermal performance of RFS to determine the intermittent operation parameters, so as to ensure the indoor thermal environment meet the requirements and achieve the energy-saving operation control.

\section{Conclusion}

Under the start-up control of RFS in the cooling mode and $T_{s a}$ regulation in the heating mode, thermal performance of radiant terminal dynamically changed.

(1) With the decrease of the temperature difference between pipe water and radiant floor, the heat exchange lessened, and the change of the $T_{f}$ came to stability. While $T_{\text {in }}$ began to decrease/increase with the effect of cooling/heating $0.5 \sim 1 \mathrm{~h}$ after imposing control to RFS.

(2) In the cooling mode, $\tau_{95} / \tau_{63}$ was greater than or equal to 2 , and the maximum $\tau_{95}$ was $13.5 \mathrm{~h}$. In the heating mode, $\tau_{95} / \tau_{63}$ was 1.6 , and the maximum $\tau_{95}$ was $8 \mathrm{~h}$. Both indicated the long response time of RFS.

(3) Compared with the start-up control in summer, $T_{s a}$ regulation in winter had a greater impact on the thermal performance of the RFS, which made the thermal response faster.

\section{Conflicts of interest}

The authors declare no potential conflicts of interest with respect to the research, authorship, and/or publication of this article.

\section{Acknowledgements}

This work was supported by the Support Plan for Outstanding Youth Innovation Team in Shandong Province (2019KJG005), National Natural Science Foundation of Shandong Province (ZR2020ME211), and National Natural Science Foundation of China (51608310).

\section{Nomenclature}

$\begin{array}{ll}Q & \text { Total heat transfer }\left(\mathrm{W} / \mathrm{m}^{2}\right) \\ S_{n} & \text { measuring point } \\ T & \text { temperature }\left({ }^{\circ} \mathrm{C}\right) \\ V & \text { flow rate }\end{array}$

Subscripts

$0 \quad$ initial temperature of the temperature change

100 final temperature of the temperature change

in indoor air

$f \quad$ floor surface

$s \quad$ surface of the walls and ceiling

sw supply water

Symbols

$\tau_{63} \quad$ time to achieve $63 \%$ of the temperature change (h)

$\tau_{95} \quad$ time to achieve $95 \%$ of the temperature change (h)

\section{References}

[1] X. Sui and X. Zhang, "Effects of radiant terminal and air supply terminal devices on energy consumption of cooling load sharing rate in residential buildings," Energy Build., vol. 49, pp. 499-508, 2012.

[2] X. Zhou, Y. Liu, M. Luo, L. Zhang, Q. Zhang, and $\mathrm{X}$. Zhang, "Thermal comfort under radiant asymmetries of floor cooling system in $2 \mathrm{~h}$ and $8 \mathrm{~h}$ exposure durations," Energy Build., vol. 188-189, pp. 98-110, 2019.

[3] J. Liu, Z. Li, M. K. Kim, S. Zhu, L. Zhang, and J. Srebric, "A comparison of the thermal comfort performances of a radiation floor cooling system when combined with a range of ventilation systems," Indoor Built Environ., vol. 29, no. 4, 2020.

[4] M. Bojić, D. Cvetković, V. Marjanović, M. Blagojević, and Z. Djordjević, "Performances of low temperature radiant heating systems," Energy Build., vol. 61, pp. 233-238, 2013.

[5] X. H. Liu, Y. I. X. Q., X. Y. Xie, and Y. Jiang, "Temperature and humidity independent control air-conditioning system and operating strategy," in International Congress of Refrigeration, 2007. 
[6] M. Andrés-Chicote, A. Tejero-González, E. Velasco-Gómez, and F. J. Rey-Martínez, "Experimental study on the cooling capacity of a radiant cooled ceiling system," Energy Build., vol. 54, pp. 207-214, 2012.

[7] M. Krajčík and O. Šikula, "The possibilities and limitations of using radiant wall cooling in new and retrofitted existing buildings," Appl. Therm. Eng., vol. 164, p. 114490, 2020.

[8] B. Ning, S. Schiavon, and F. S. Bauman, "A novel classification scheme for design and control of radiant system based on thermal response time," Energy Build., vol. 137, pp. 38-45, 2017.

[9] M. Krajčík and O. Šikula, "Heat storage efficiency and effective thermal output: Indicators of thermal response and output of radiant heating and cooling systems," Energy Build., vol. 229, p. 110524, 2020.

[10] A. Merabtine, A. Kheiri, S. Mokraoui, and A. Belmerabet, "Semi-analytical model for thermal response of anhydrite radiant slab," Build Environ., vol. 153, pp. 253-266, 2019.

[11] J. Liu, "Optimization of Control Strategies for the Radiant Floor Cooling System Combined with Displacement Ventilation: A Case study of an Office Building in Jinan, China," Int. J. Archit. Eng. Techno, vol. 6, pp. 33-48, 2019.

[12] R. Hu and J. L. Niu, "Operation dynamics of building with radiant cooling system based on Beijing weather," Energy Build., vol. 151, pp. 344-357, 2017.

[13] X. Sui, H. Wang, J. Yan, and H. Guo, "Optimal Intermittent Regulation of Tubes-embedded Building Envelope Cooling System," Procedia Eng., vol. 205, pp. 2639-2646, 2017.

[14] J. Liu, "A Transient Two-dimensional CFD Evaluation of Indoor Thermal Comfort with an Intermittently-operated Radiant Floor Heating System in an Office Building," Int. J. Archit. Eng. Techno, vol. 7, pp. 62-87, 2020.

[15] H. Tang, P. Raftery, X. Liu, S. Schiavon, J. Woolley, and F. S. Bauman, "Performance analysis of pulsed flow control method for radiant slab system," Build Environ., vol. 127, pp. 107-119, 2018.
[16] Annual Report on China Building Energy Efficiency . 2014 (Building Energy Research Center of Tsinghua University). China Architecture \& Building Press, 2014.

[17] X. Liu, T. Zhang, X. Zhou, and H. Tang, Radiant Cooling. Beijing: China Architecture \& Building Press, 2019. 